\title{
Propagation of a confined explosion to an external cloud
}

\author{
Daubech Jérôme $^{\mathrm{a}}$, Proust Christophe ${ }^{\mathrm{a}, \mathrm{b}}$, Lecocq Guillaume ${ }^{\mathrm{a}}$ \\ E-mail: jerome.daubech@ineris.fr \\ ${ }^{a}$ Institut de l'environnement industriel et des risques (INERIS, Verneuil en Halatte, France) \\ ${ }^{b}$ Sorbonne Universities, Technological Univ. Of Compiègne, ESCOM, TIMR (Compiègne, \\ France)
}

\begin{abstract}
Since the pioneering work of Harrison and Eyre (1986), the existence of secondary or external explosion outside explosion vents is recognized. It was later shown (Proust, 2004, 2010) that the phenomenon is rather systematic and that this explosion can be much more powerful than the internal explosion particularly when the mixture is very reactive. But today, the understanding of the formation of the external cloud and its subsequent combustion remains largely outstanding. Very rapid burning was noticed and significant UVCE pressure effects. In some circumstances, a preexisting flammable cloud encompasses the vented vessel, like in Buncefield for instance. What would happen if the cloud is ignited inside the vessel resulting in an external explosion developing inside the preexisting flammable cloud ? In this paper, new information is presented about the physics of the external explosion and the subsequent combustion of outside cloud. Experiments and numerical simulations were performed.
\end{abstract}

Keywords: flame propagation, confined explosion, external explosion

\section{Introduction}

The Buncefield accident occurred on 11th December 2005 at 6 h30 inside an oil depot. The overfilling of a tank resulted in a 1800 tons of gasoline to cascade down the side of the tank inside the bund $\left(5000 \mathrm{~m}^{3}\right)$. A few meters thick vapour cloud was formed and spread far away from the tank covering a zone $120000 \mathrm{~m}^{2}$. The cloud was most probably ignited in the pump house, resembling a sort of concrete bunker (Buncefield investigation report, 2008).

From the damages, overpressures on the order of 1 bar should have occurred inside the cloud and window were broken up to $1,5 \mathrm{~km}$ from the pump house.

An important research programme was launched in order to explain the damages and trace back the scenario and the phenomenology. The investigation of the acceleration of the flame by obstacles (trees) was favoured in this programme but other potential mechanisms were proposed but not analysed deeply. One of them is "the confined ignition" of the cloud inside the pump house and the transmission to the outside via some external explosion mechanism.

Apart from this specific context, the situation depicted above is quite common in the industry and there is not much information available to take it into account within the frame of safety studies.

When a gas explosion is triggered inside a vessel provided with an opening, most of the flammable cloud is expelled outside. A "bubble" of flammable cloud is formed on the axis of 
the vent and explodes violently when the flame penetrates this bubble. This phenomenon is called external deflagration or secondary explosion.

This was identified when designing venting methods for buildings (Cooper et al., 1986, Harrison et Eyre, 1987, Proust et Leprette, 2010). Past experiments (Maxworthy, 1972, 1977, Proust et Leprette, 2010) show that this phenomenon is almost systematic. The external explosion dominates the pressure dynamics if the vent area represents at least $20 \%$ of the inner surface of the vessel. At least for compact vessels, the expelled cloud has all the characteristics of a "vortex bubble" as described by Maxworthy (Fig.1). The vortex ring peripheral velocity and the bubble average propagation velocity are on the same order of magnitude than that of gas velocity at the vent exit.

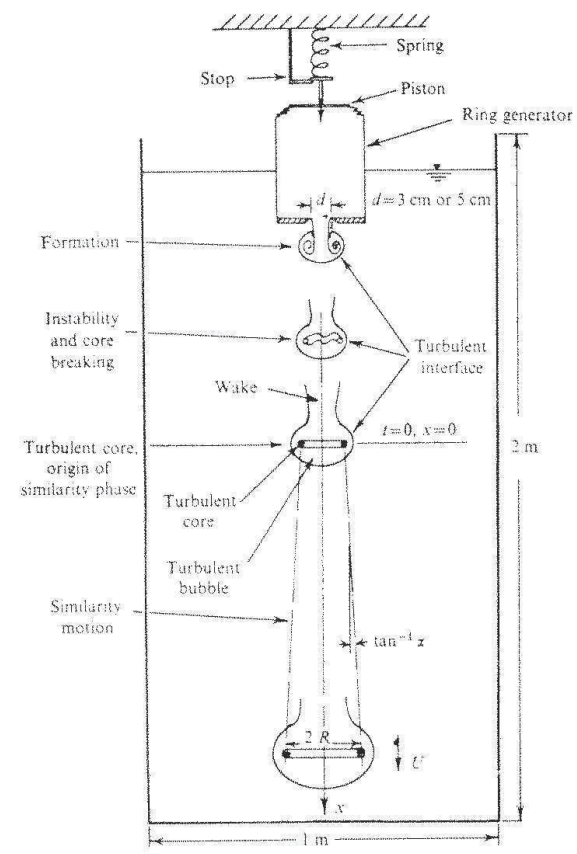

Fig. 1: Eddy bubble (Maxworthy, 1972, 1977).

These experiments also show that the external explosion occurs when the vortex ring burns. The expansion velocity of "fire ball" seems to depend more on the propagation velocity of bubble than on the reactivity of the mixture. Nevertheless, the details of the explosion mechanisms are not well known and the available data are not sufficient. They do not in particular provide means to answer the question raised.

In this paper the results of research program are presented. Not only the flame propagation mechanism was investigated but also some numerical simulations were performed to help analysis the data and proposing a modeling strategy for safety engineering.

\section{Testing}

\subsection{Setup}

The experimental set-up is composed a $4 \mathrm{~m}^{3}$ explosion chamber connected to a $54 \mathrm{~m}^{3}$ unconfined volume (Fig. 3) via a square vent. Both volumes are filled with a stoichiometric propane-air mixture. The $54 \mathrm{~m}^{3}$ volume is approximately a $3 \mathrm{~m} \times 3 \mathrm{~m} \times 6 \mathrm{v}$ m steel frame 
built against a concrete wall and covered with a thin transparent plastic sheet to maintain the flammable cloud.

The explosion chamber (Fig. 2) is $2 \mathrm{~m}$ long, $2 \mathrm{~m}$ high and $1 \mathrm{~m}$ deep, representing an inner volume of $4 \mathrm{~m}^{3}$. Only one central vent area was arranged on one small side (1 $\left.\mathrm{m} \times 2 \mathrm{~m}\right)$. Three sides are provided with large transparent plates ( $2 \mathrm{~cm}$ PPMA for the front side, the top, the small side containing the vent). The combustible gas is injected directly from compressed commercial bottles in the lower part of the chamber and mixed by an electrically driven fan (the fan is stopped well before ignition so that the mixture is quiescent). A similar technique is used for the $54 \mathrm{~m}^{3}$ volume. The concentration distribution is controlled using oxygen analyzers sampling the atmosphere. To ease the observation of the vortex bubble, the mixture in the chamber is seeded with microparticles of ammonium chloride during the preparation of the mixture. Ignition is achieved using an electrical spark $(10 \mathrm{~mJ})$ or a pyrotechnical match $(60 \mathrm{~J})$. Six piezoresistive gauges (KISTLER 0-10 bar accuracy $\pm 0,1 \%$ ) are used to measure the pressure evolution inside and outside. Further the formation of the cloud in front of the vent and the propagation of the flame are filmed using a high speed video system (PHOTRON Fastcam). The vent area is covered with a very thin plastic sheet held with magnetic tapes.

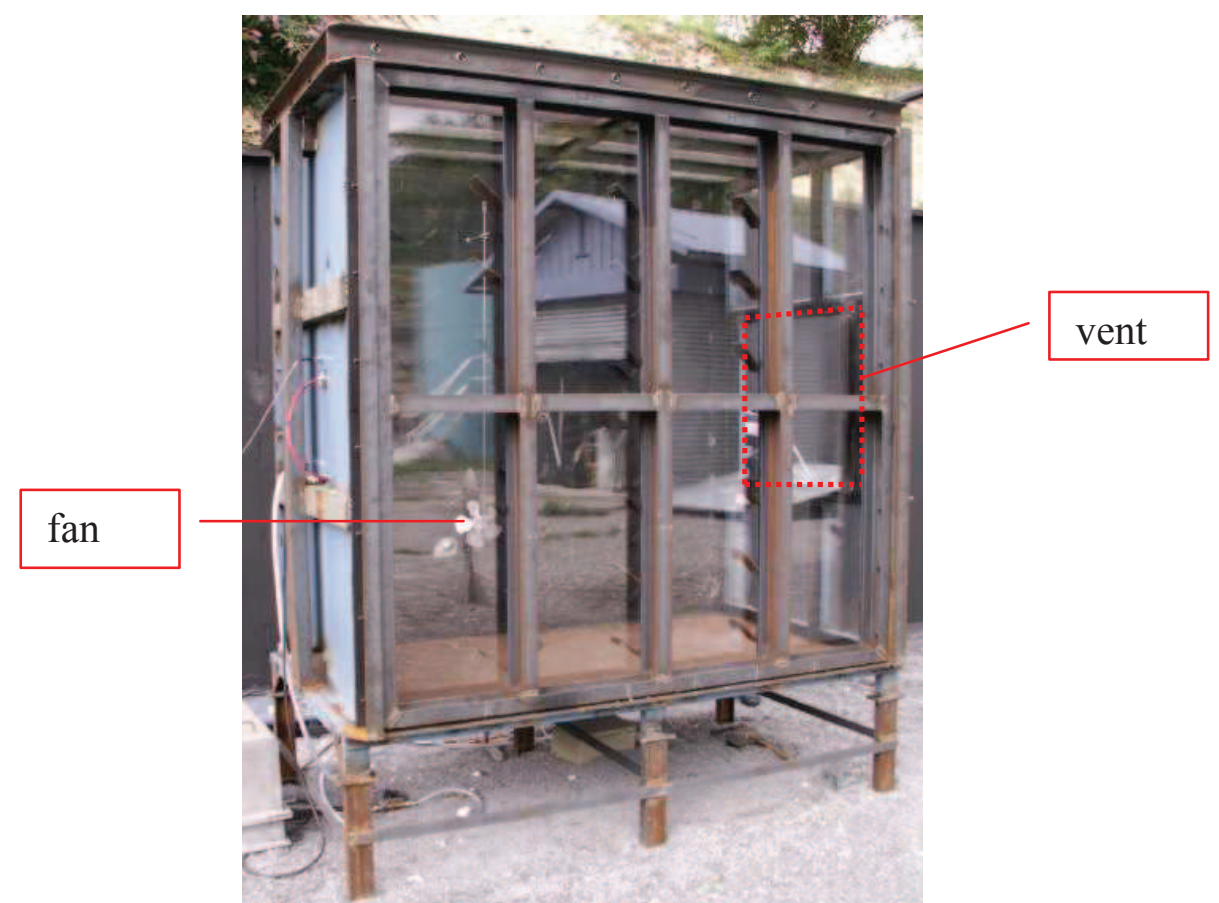

Fig. 2: The $4 \mathrm{~m}^{3}$ chamber (2 $m$ high, $2 \mathrm{~m}$ high, $1 \mathrm{~m}$ deep).

Two sensors are installed inside the $4 \mathrm{~m}^{3}$ chamber (Fig. 4) : one near the ignition point and the other in the middle of the back large side. Three additional gauges are installed on profiles supports outside the explosion chamber : one on the axis of the vent at $3 \mathrm{~m}$ distance (so inside the $54 \mathrm{~m}^{3}$ volume) and the two others perpendicular to the vent axis at $5 \mathrm{~m}$ and $10 \mathrm{~m}$ from the first one. 


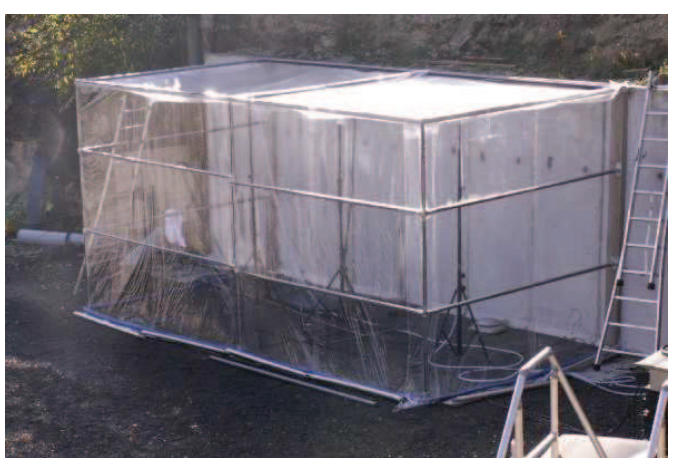

Fig. 3: $54 \mathrm{~m}^{3}$ volume

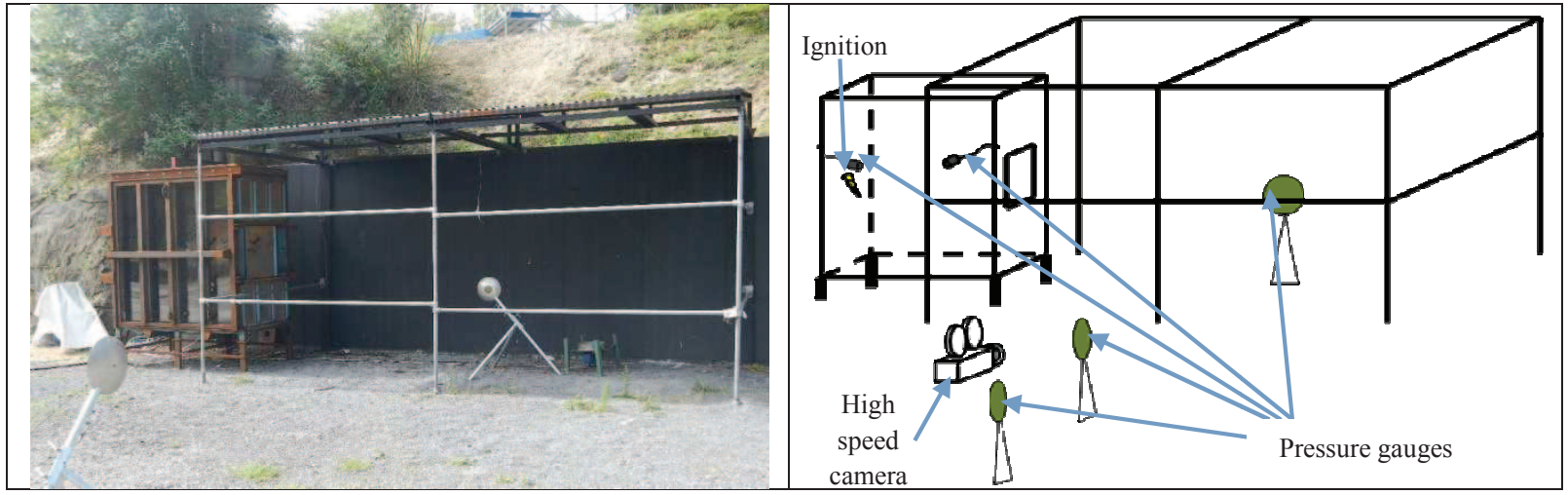

Fig. 4: Picture and scheme of instrumentation

Two (square) vent sizes were studied, $0.5 \mathrm{~m}^{2}(0.7 \mathrm{~m} \times 0.7 \mathrm{~m})$ and $0.04 \mathrm{~m}^{2}(0.2 \mathrm{~m} \times 0.2 \mathrm{~m})$

Six tests were performed (Table 1). Five with propane-air mixtures were done and an additional one with a lean hydrogen-air mixture having the same burning velocity that the stoichiometric propane air mixture..

Table 1: Tests configurations

\begin{tabular}{|c|c|c|c|c|}
\hline$N^{\circ}$ of Test & Vent size (m x m) & Volume & Mixture & Ignition \\
\hline 1 & / & $54 \mathrm{~m}^{3}$ volume only & $4 \% \mathrm{v} / \mathrm{v}$ propane-air & $\begin{array}{l}\text { Pyrotech }(60 \mathrm{~J}) \text { near the floor } \\
\text { and in the middle of the wall }\end{array}$ \\
\hline 3 & $0.2 \mathrm{~m} \times 0.2 \mathrm{~m}$ & $4 \mathrm{~m}^{3}$ chamber only & $4 \% \mathrm{v} / \mathrm{v}$ propane-air & Pyrotech (60 J) \\
\hline 4 & $0.7 \mathrm{~m} \times 0.7 \mathrm{~m}$ & $\begin{array}{c}4 \mathrm{~m}^{3} \text { chamber } \\
\text { volume }\end{array}$ & $4 \% \mathrm{v} / \mathrm{v}$ propane-air & Pyrotech (60 J) \\
\hline 6 & $0.7 \mathrm{~m} \times 0.7 \mathrm{~m}$ & $4 \mathrm{~m}^{3}$ chamber only & $16.5 \% \mathrm{v} / \mathrm{v}$ hydrogen-air & Elect. $(10 \mathrm{~mJ})$ \\
\hline
\end{tabular}

\subsection{Chamber only}

In this situation the external atmosphere around the chamber is not flammable (air only). Tests 2, 3 and 6 are concerned.

Test 6 (with hydrogen) is first considered (Fig. 5). The shape of the external cloud is clearly that of a vortex bubble. The edges of the bubble are very sharp suggesting very little turbulent diffusion from the bubble to the external atmosphere despite the very high Reynolds number 
$\left(10^{6}\right)$. This would imply that the source of overpressure outside would be limited to the bubble explosion (no turbulent transfer toward the external atmosphere of the ball). The maximum external overpressure is reached $140 \mathrm{~ms}$ after ignition in the chamber, which corresponds to the moment when the flame reaches the vortex ring in the center of the bubble. The combustion velocity deduced from the Video and the overpressures is around $65 \mathrm{~m} / \mathrm{s}$. At 148 $\mathrm{ms}$, when the flame reaches the edge of the bubble, the external overpressure is zero. The production of pressure effects seems to be strictly limited to what happens in the center of the bubble.

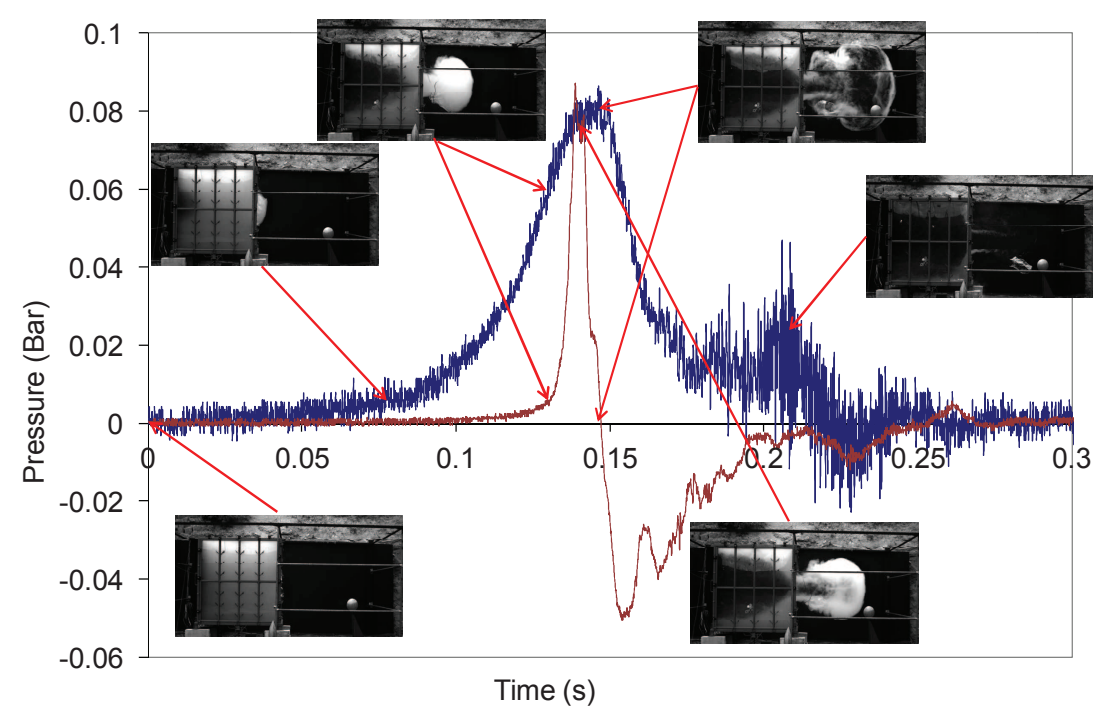

Fig. 5: Internal overpressure evolution, flame evolution and the external overpressure at $2 m$ (Test 6 : rear ignition, $\% \mathrm{H2}=16.5$, homogeneous, vent area $0.5 \mathrm{~m}^{2}$ )

Test 2 was performed in the same conditions expect the mixture which is now propane-air (Fig. 6). Again the burning velocities in both tests are similar. The external pressure pulses are very resembling.

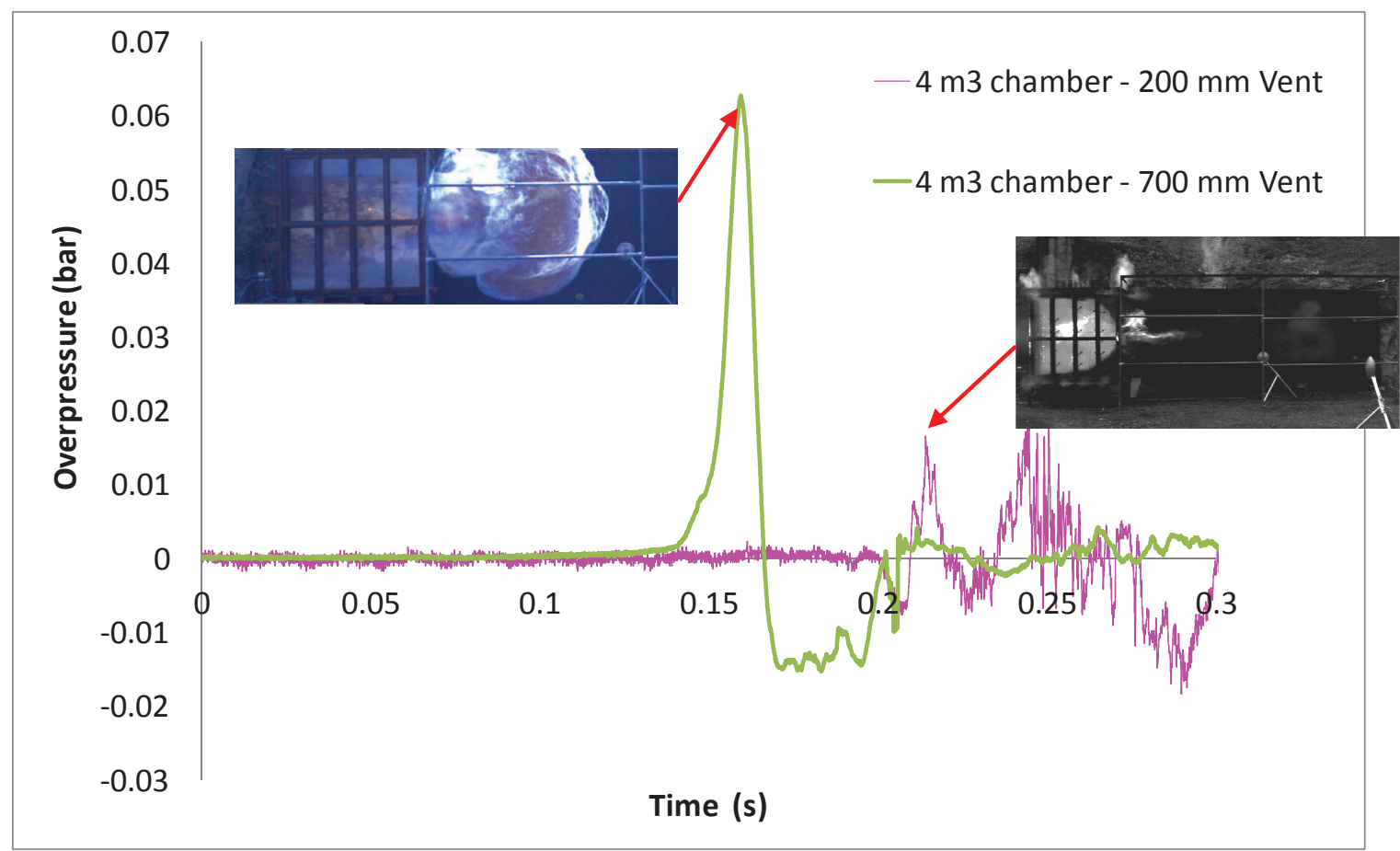

Fig. 6: Overpressures measured at $3 \mathrm{~m}$ from the vent for the external explosion developed from the $4 \mathrm{~m}^{3}$ vessel only with the $700 \mathrm{~mm}$ vent (test 2-green curve) and the $200 \mathrm{~mm}$ vent (test 3 - pink curve) 
We test the influence of the vent size on the strength of external explosion if the external atmosphere is flammable.

\subsection{Unconfined volume only}

In this situation the chamber is not used and the cloud is ignited directly inside the $54 \mathrm{~m}^{3}$ volume. The results are presented in Fig. 7. The development is very slow (600 ms to reach the maximum overpressure inside the volume which remains very modest : 8-10 mbar. Knowing that the burned volume characteristic size is twice that of the unburned volume, the typical path the flame front has to propagate on to reach the open atmosphere and extinguish is $2 \times 54^{1 / 3}=7,5 \mathrm{~m}$. The related combustion time should be close to that corresponding to the maximum overpressure $(0.6 \mathrm{~s})$ so that the average flame velocity would be about $13 \mathrm{~m} / \mathrm{s}$. If the explosion were perfectly unconfined the overpressure inside the burnt gases would be $2 \mathrm{x}$ $1.2 \times 13^{2}=400 \mathrm{~Pa}$. Almost the double was recorded suggesting potentially some influence of the confinement. Nevertheless, $13 \mathrm{~m} / \mathrm{s}$ is three times that of the expansion of the burnt gases ( $0.55 \times 7.5$ where 7.5 is the expansion ratio of the burnt gases) suggesting a strong influence of instabilities.

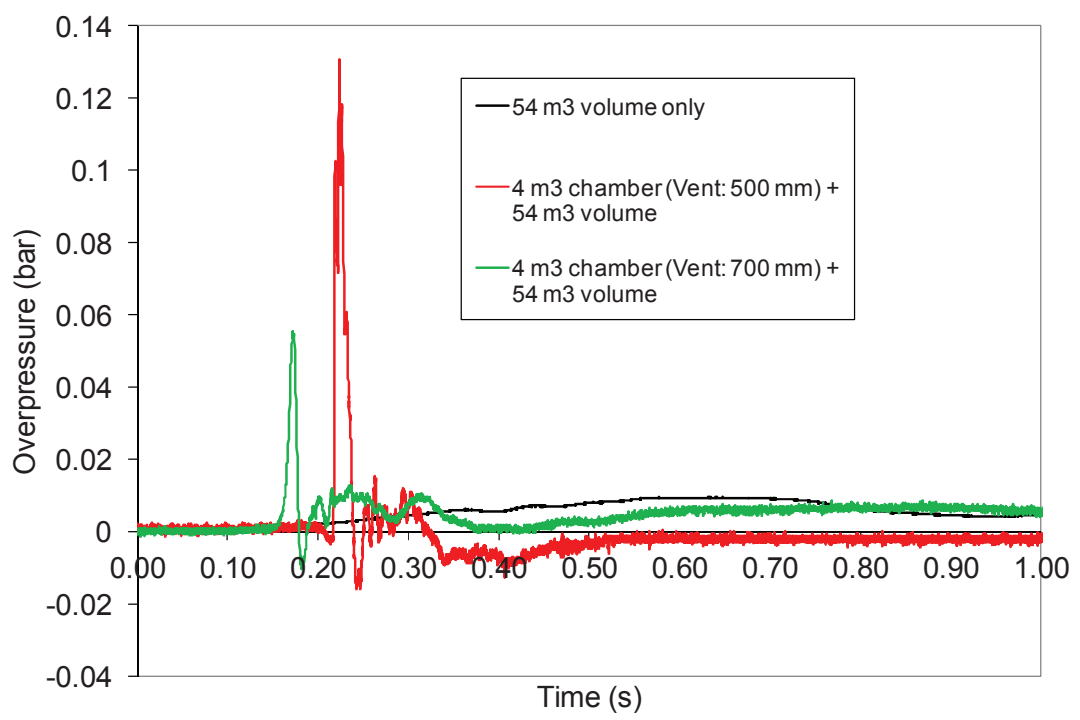

Fig. 7: Overpressure in $54 \mathrm{~m} 3$ volume

\subsection{Propagation from the vessel to the unconfined volume}

An illustration is presented on the figure above. Although the total available energy is the same, the "confined ignition" scenario lead to a much more significant pressure effect (inside the $54 \mathrm{~m}^{3}$ cloud). The largest effects are measured with the smaller vent size : 55 mbar for the $0.7 \mathrm{~m}$ square vent and $130 \mathrm{mbar}$ for the $0.2 \mathrm{~m}$ square vent. Why is it so ?

Considering Fig. 8 and comparing the tests with the larger vent, it is clear that the presence of the combustible atmosphere around the vortex bubble does not change the pressure effect. In fact the combustions in the vortex bubble and in the rest of the $54 \mathrm{~m}^{3}$ cloud are totally decoupled. This might be a consequence of the observation given above about the "sharpness" of the vortex bubble suggesting little intermixing and even little turbulence. This point is further analysed in the next section. 


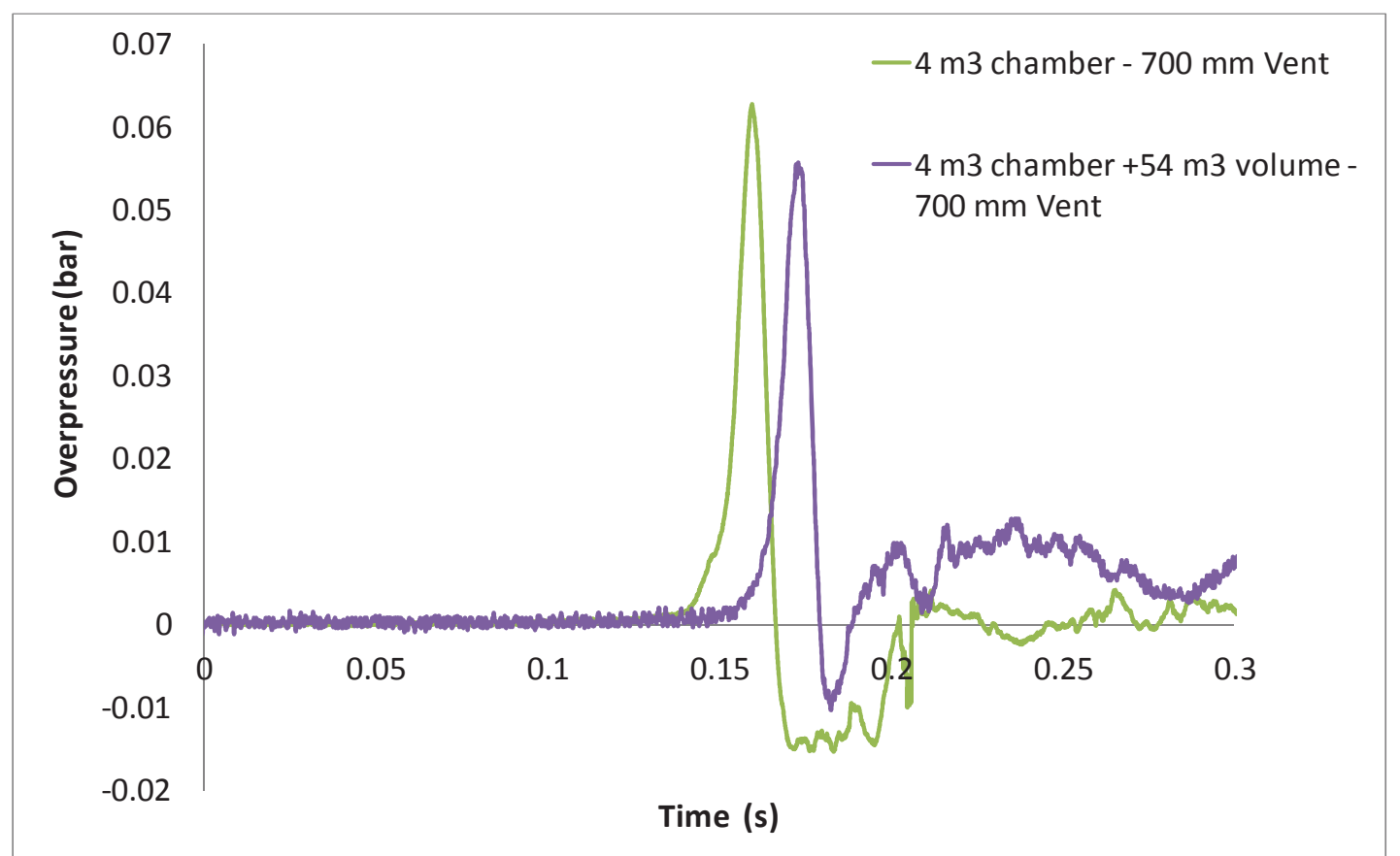

Fig. 8: Overpressures measured at $3 \mathrm{~m}$ from the vent for the external explosion developed from the $4 \mathrm{~m}^{3}$ vessel only (test 2) and the explosion of $54 \mathrm{~m}^{3}$ volume ignited by the $4 \mathrm{~m}^{3}$ chamber explosion (test 4)

If the situation were the same with the smaller vent, even smaller overpressure effect would have been measured. But this is not the case. In test 5 (fig 9), the unburned gases pushed outside does not form a vortex bubble but more a jet which length grows with the discharge time (up to $208 \mathrm{~ms}$ ). The maximum length of this unsteady jet is about $3.5 \mathrm{~m}$. Between 208 and $220 \mathrm{~ms}$, the flame propagates rapidly in the jet zone. This is during this period that the maximum overpressure, about $120 \mathrm{mbar}$, is produced. After $220 \mathrm{~ms}$, the flame velocity decreases (fig 10) and the rest of the $54 \mathrm{~m}^{3}$ burns off.

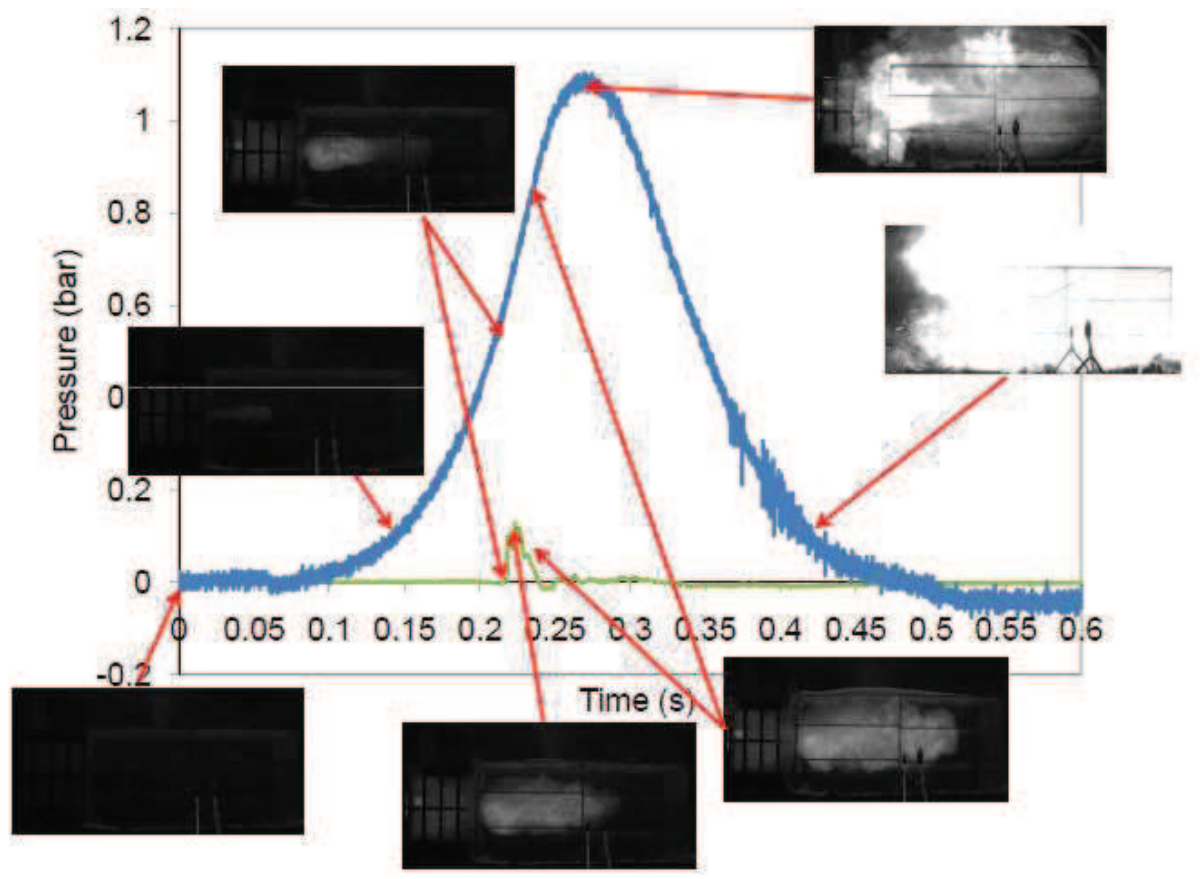

Fig. 9: Internal (blue curve) and external (green curve) overpressures. Test 5: $4 \% \mathrm{C}_{3} H_{8}$-air mixture, homogeneous, rear ignition, $0.04 \mathrm{~m} 2$ vent 


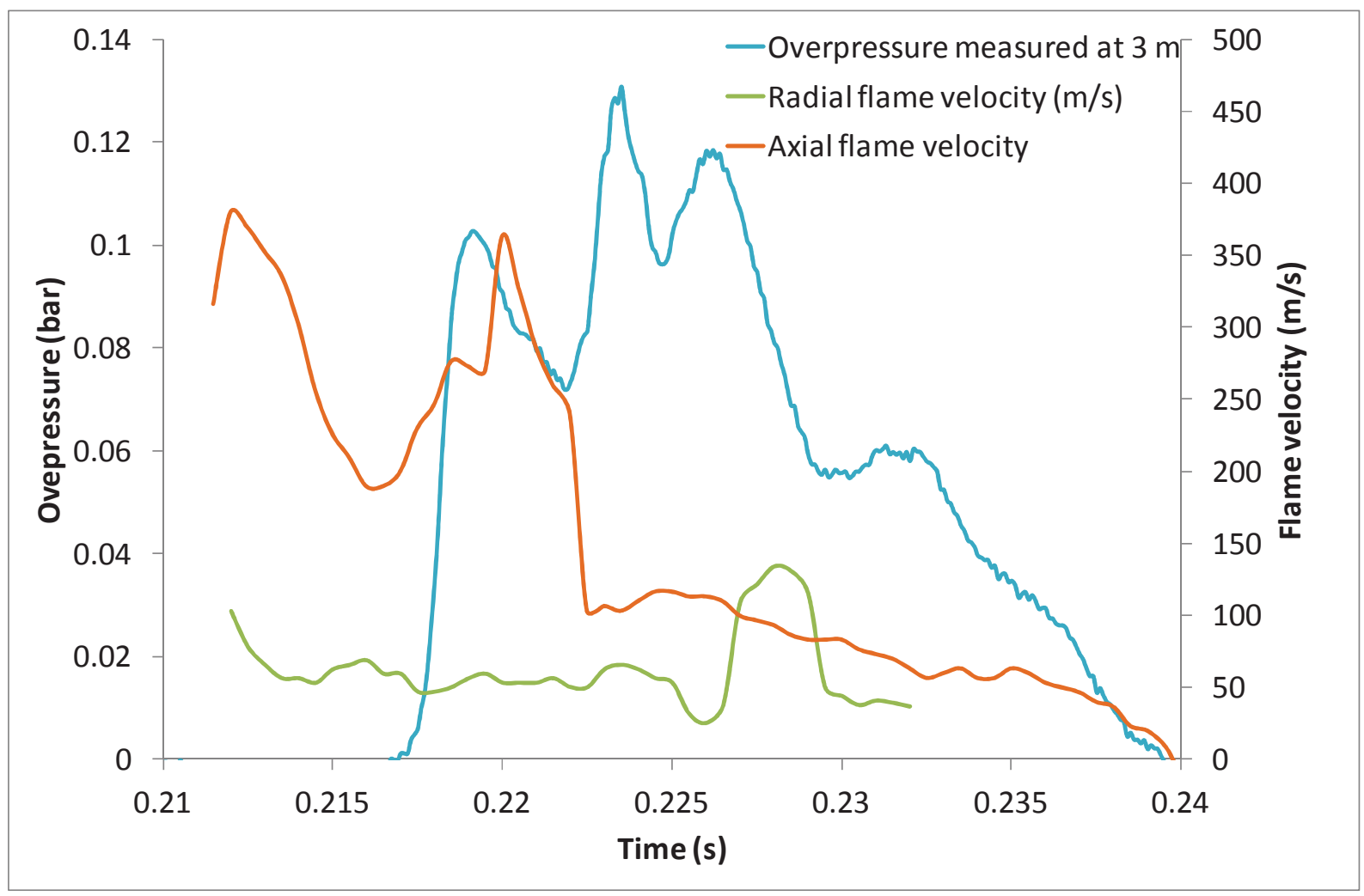

Fig. 10: Maximum flame velocity along the vent axis (orange curve) and perpendicular to the vent axis (green curve) and external overpressure (in the $54 \mathrm{~m}^{3}$ volume)

Note, the maximum overpressure in the $54 \mathrm{~m}^{3}$ volume is about $130 \mathrm{mbar}$, which corresponds to a combustion velocity of $90 \mathrm{~m} / \mathrm{s}$. The axial flame propagation velocity deduced from the fast camera movie is much higher $350 \mathrm{~m} / \mathrm{s}$ and the radial flame propagation velocity is around $70 \mathrm{~m} / \mathrm{s}$. This apparent mismatch is discussed later.

\section{Discussion}

\subsection{Aerodynamics of the unburnt gases flowing out from the vent}

The turbulence generated (or not generated...) by the unbunt gases flowing out from the vent is the central piece to understand what is described above.

To discuss this point, the resources offered by Computational Flow Dynamics were used. A uRANS (Unsteady Reynolds Average Navier Stokes) compressible formulation was selected because the Reynolds decomposition proposed "forces" the turbulence to appear (even when the flow should not be turbulent). In the present configuration with a mostly mono directional flow without obstacles/walls outside this formulation appears reasonable. The flame propagation is not modeled and the compression effect due to the combustion in the chamber is mimicked imposing, via a fictitious piston an increase of the internal pressure compliant to the experimental curve. The solver SonicFoam from OpenFoam software was used using a 500000 cells mesh and two planes of symmetry (dimensions: $5 \mathrm{~m} \mathrm{x} 1.5 \mathrm{~m} \mathrm{x} 2 \mathrm{~m}$ ).

Test 6 is represented on Fig. 11 comparing the experimental data with the computations. The grey scale in the computation is the mixture fraction ( 1 for the gas coming out from the chamber and 0 for the outside atmosphere). Not that the results of the computations show a vertical cut, whereas in the experiment all the vertical planes are integrated. Thus, only the outer dimensions and the dynamics can be compared. A reasonable agreement is observed. 
The global geometry and dynamic of vortex bubble formation seem well reproduced giving some confidence into a more detailed analysis of the simulated aerodynamics.

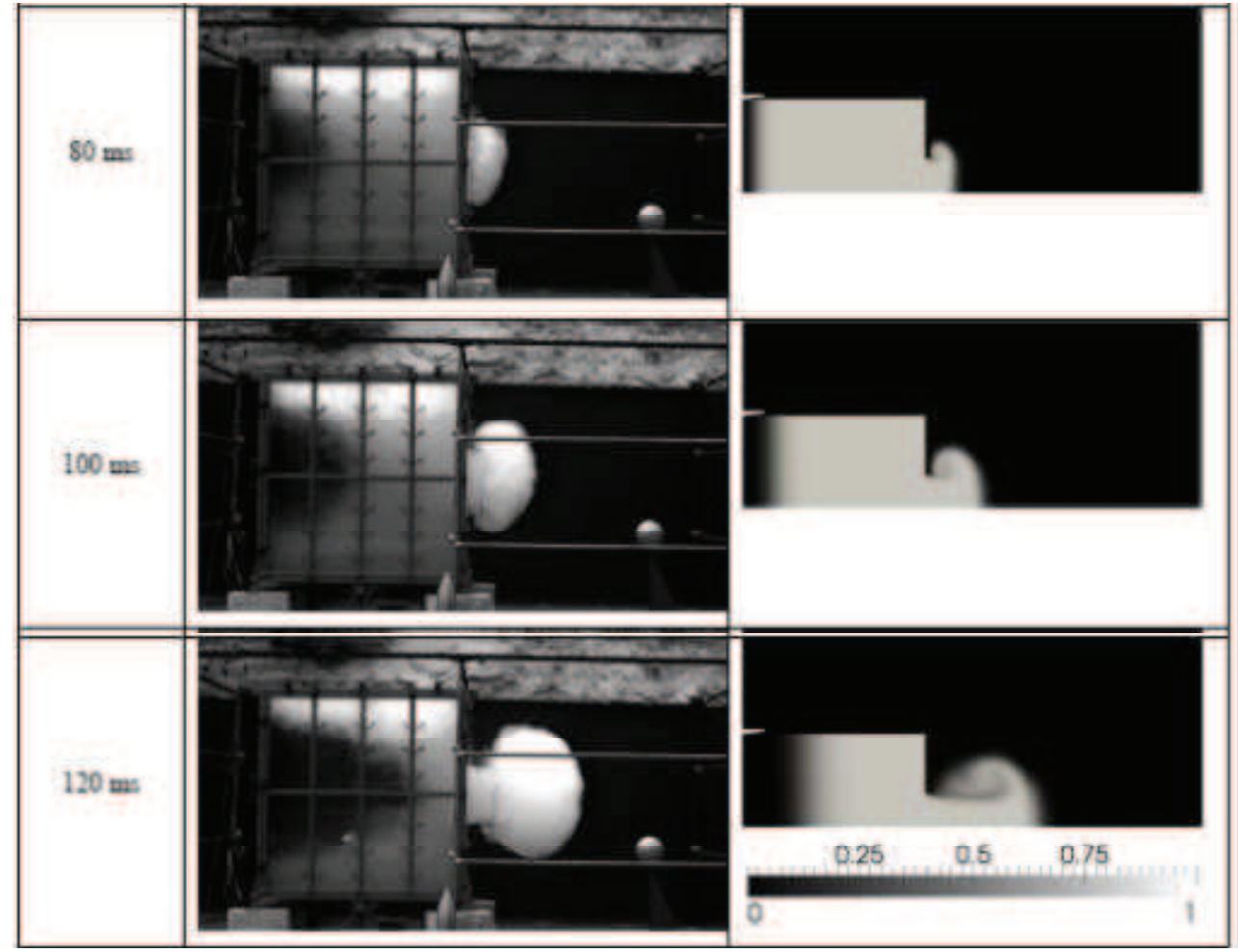

Fig. 11: Formation of external cloud test 6-experiment and simulation

There is in the periphery of the column of unburnt gases flowing out from the vent a swirling movement entraining some outside atmosphere but in small quantities. The border between the outside atmosphere and the unburnt gases seems sharp until the very last moment indicating a small effect of turbulent mixing being at work. On Fig. 12, the swirl developing on the edge of the unburnt gases column is below the atmospheric pressure, indication vortex ring swirling over itself. The turbulence is trapped in boundaries and occupies only a very little portion of the structure. Globally this structure is behaving very similarly to a laminar vortex bubble even though the size and velocity conditions would suggest a highly turbulent flow. Note also that the outside atmosphere is not turbulized at all.
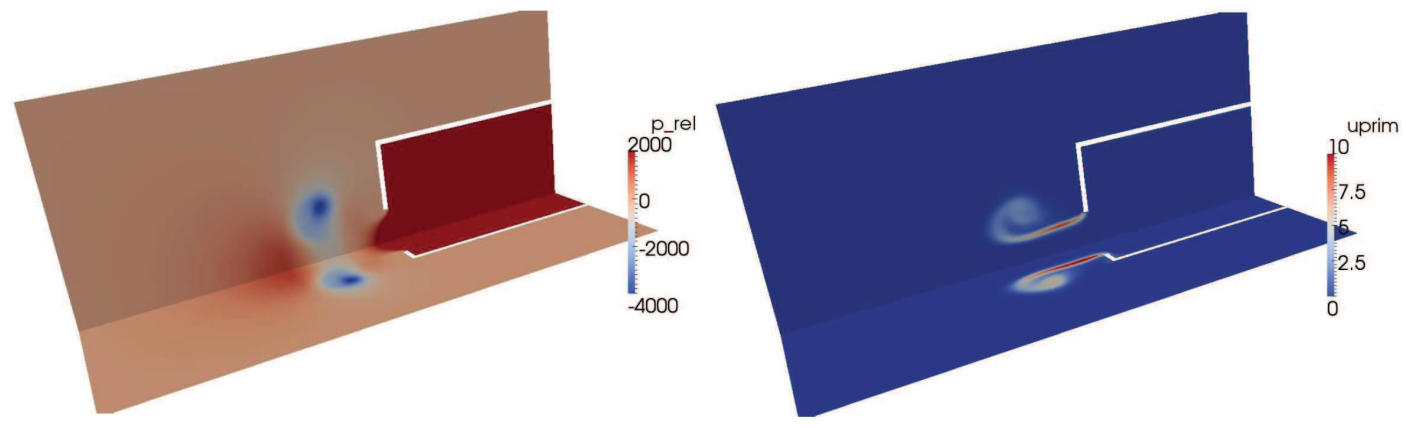

Fig. 12: Pressure field and turbulent velocity field in the external cloud

Exactly the same conclusions were obtained with test 2 (Fig. 13 and 14) with a refined aerodynamic calculation. In particular, the average flow velocity is also showing that the outside atmosphere is not much disturbed. The average velocities may be very large $(100 \mathrm{~m} / \mathrm{s})$ but the turbulence is very limited. The flow velocity at the exit is about $100 \mathrm{~m} / \mathrm{s}$ but the 
material velocity at the apex of the bubble is about half of this which is exactly what should be expected from the laminar vortex theory (Mc Cormack, 1977, Ishizuka, 1998). Clearly, in this situation, turbulence is starting to develop and spread into the bubble. If more time would have be left to the flow for developing, the vortex bubble would have been destroyed.

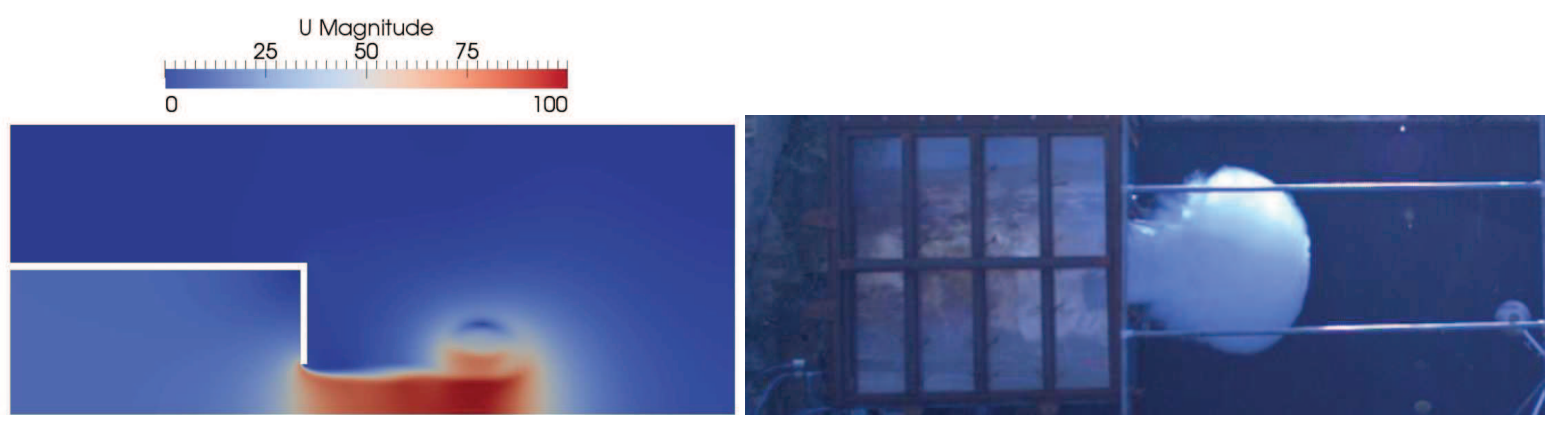

Fig. 13: Simulated flow field in front of the vent and experimental observation (test 2)
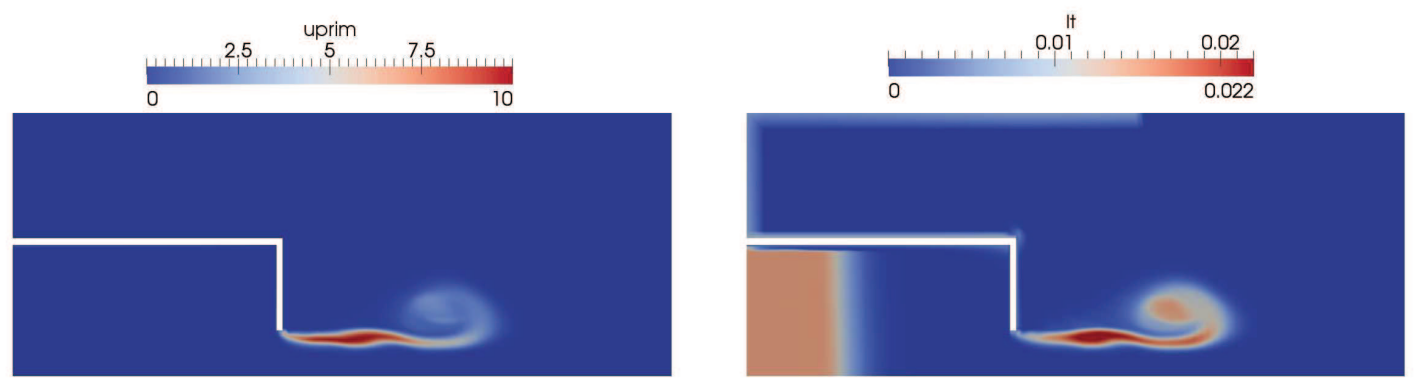

Fig. 14: Turbulent intensity $U^{\prime}(\mathrm{m} / \mathrm{s})$ and turbulent length scale lt $(\mathrm{m})$ (test 2)

This occurs with the smaller vent (test 3 and 5) If the vent size is $0.2 \mathrm{~m} \mathrm{x} 0.2 \mathrm{~m}$, (Fig. 15). The computation show the formation of a vortex bubble (max diameter $50 \mathrm{~cm}$ ), pushed by the flow along the axis of the vent and degenerating in a jet with an aperture angle of $10^{\circ}$. The maximal extension of the jet at $210 \mathrm{~ms}$ (when the flame goes outside from the experiments) is about $3.5 \mathrm{~m}$. this is fully in line with the experimental observations. Note the maximum velocity on the axis is about $260 \mathrm{~m} / \mathrm{s}$. A significant entrainment of the outside atmosphere by the jet is observed. At time $210 \mathrm{~ms}$, the volume of the jet is $1 \mathrm{~m}^{3}$ which is more than ten times that of the initial vortex bubble.

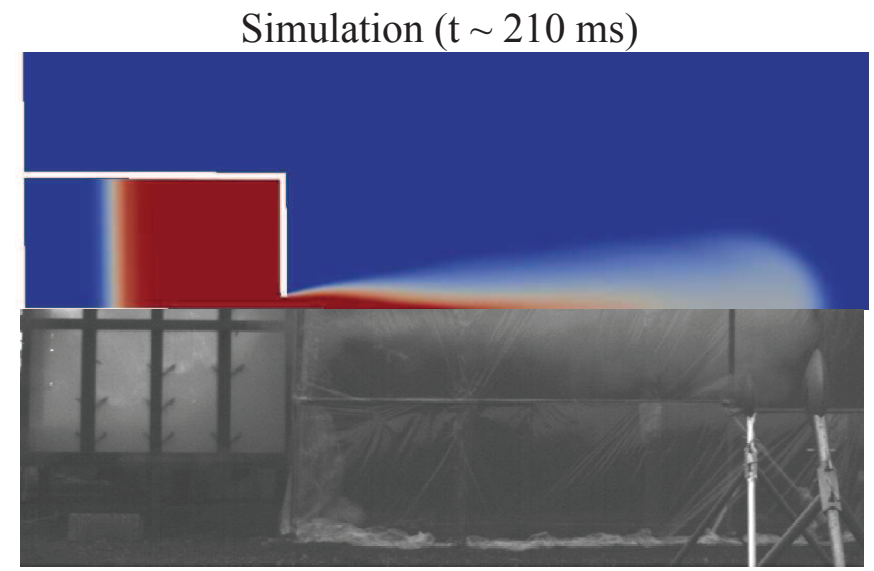

Experiment $(\mathrm{t} \sim 210 \mathrm{~ms})$ 

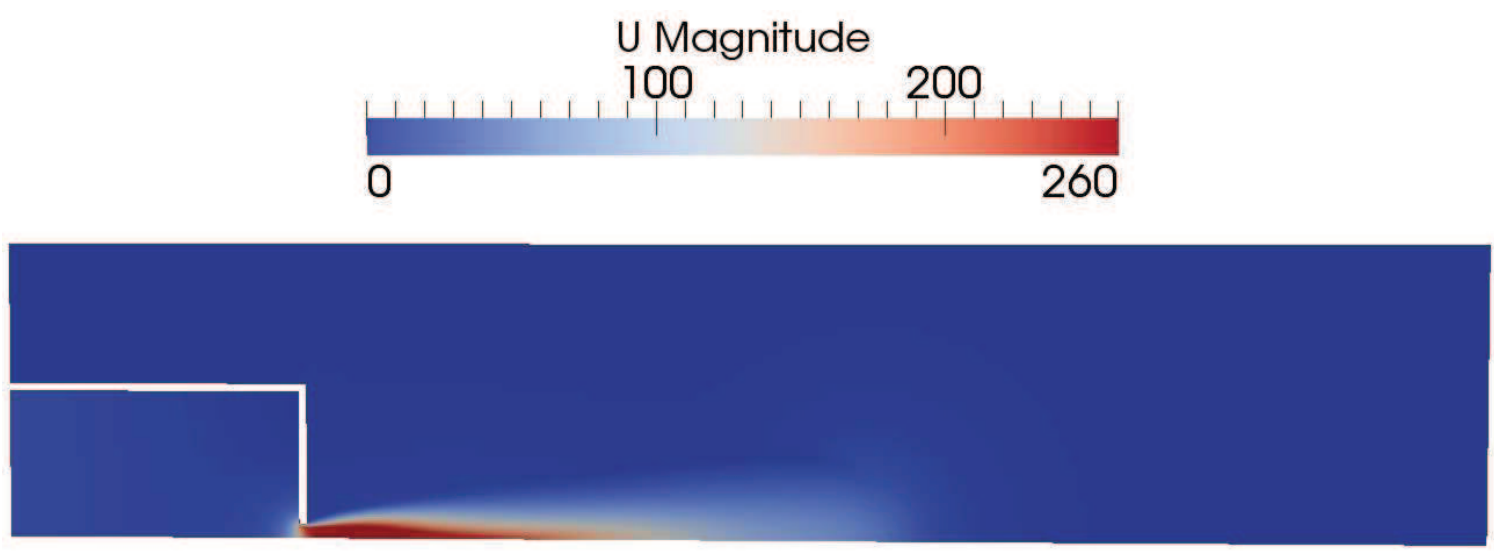

Fig. 15: Flow velocity in the $54 \mathrm{~m}^{3}$ chamber at $210 \mathrm{~ms}$ (test 5)

A very significant amount of turbulence is generated (Fig. 16: up to $20 \mathrm{~m} / \mathrm{s}$ with a length scale of $10 \mathrm{~cm}$ at $3 \mathrm{~m}$ from the vent) and spreads throughout all the jet. A steady jet (Chaineaux, 1993) with the same outlet conditions ( 0.2 diameter, $260 \mathrm{~m} / \mathrm{s}$ outlet velocity) would provide at $3 \mathrm{~m}$ on the axis a turbulent intensity of about $25 \mathrm{~m} / \mathrm{s}$ and an integral length scale of the turbulence of $0.25 \mathrm{~m}$. The figures are reasonably in line suggesting a steady jet approach might be used.

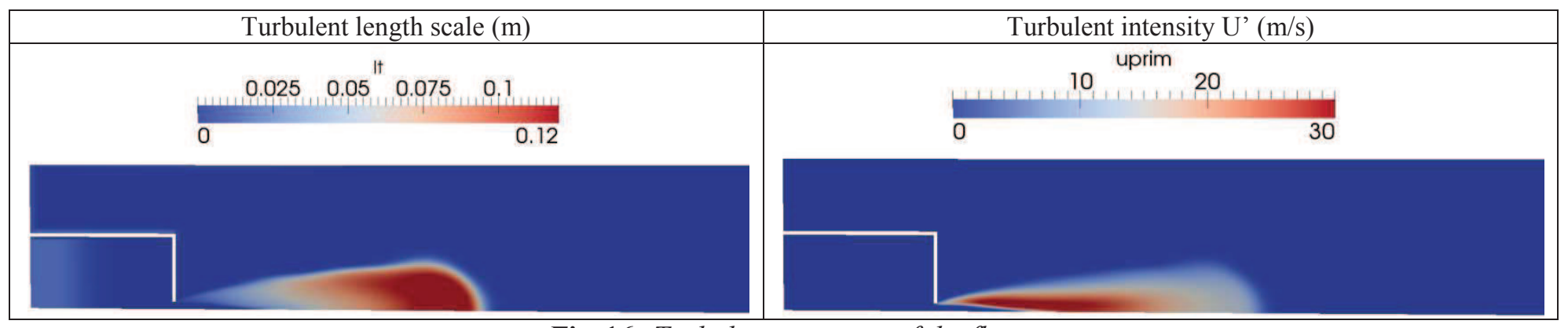

Fig. 16: Turbulent structure of the flow

\subsection{Combustion of the unburnt gases flowing out from the vent}

With the larger vent, the vortex bubble is ignited before its disruption. Simulations suggest a complete decoupling between the aerodynamics of the vortex and that of the outside atmosphere. The bubble may explode strongly while the rest of the flammable atmosphere outside may burnt gently as shown by the experiments. But since the level of turbulence inside the vortex bubble is so small, why is it that the explosion of the bubble is so violent (expansion velocity of the bubble amounting about $60 \mathrm{~m} / \mathrm{s}$ ) ? Proust once suggested (Proust, 2010) an alternative mechanism to the standard outward flame expansion may be at work. Present data give some indications. When the flame rushes outside the chamber, it should be convected by most rapid stream line which is located along the vent axis until the apex of the vortex bubble where it should be slowed down but the local overpressure (stagnation zone between the outside atmosphere and the progressing bubble) and deviated sidewise towards the vortex ring. Due to the depression zone existing inside the vortex ring the flame front might be sucked in forcing a fast circumferential propagation. Note from Fig. 12 that the average depression in the vortex ring is $2000 \mathrm{~Pa}$ and the corresponding suction velocity would be $57 \mathrm{~m} / \mathrm{s}$ which is very close to the expansion velocity of the bubble. If this model applies, 
the expansion velocity in the vortex bubble should not depend much on the burning properties of the mixture. The combustion mode still seems outstanding, may be a sort of fast flame.

With the smaller vent, the vortex bubble is destroyed before its ignition and a jet is produced. Measurement show an axial flame velocity as large as $350 \mathrm{~ms} /$ whereas the measured overpressure would suggest $100 \mathrm{~m} / \mathrm{s}$. In fact the jet velocity is about $260 \mathrm{~m} / \mathrm{s}$ indicating the contribution of the burnt gas expansion to the axial flame velocity would be the difference $350-260=90 \mathrm{~m} / \mathrm{s}$ in reasonable agreement with the overpressure measurements. It is interesting to notice that the corresponding burning velocity is about $15 \mathrm{~m} / \mathrm{s}$. It is possible to estimate what would be the turbulent burning velocity if for instance the Gülder correlation were used together with the calculated turbulent characteristics. On average (vomumetric average) throughout the jet, the turbulence intensity is about $15 \mathrm{~m} / \mathrm{s}$ and the integral length scale $0.1 \mathrm{~m}$.

$$
\frac{S_{t}}{S_{l}}=0,7 \cdot\left(\frac{u^{\prime}}{S_{l}}\right)^{0,75} \cdot\left(\frac{L_{t}}{\delta_{l}}\right)^{0,25}
$$

We calculate a characteristic turbulent burning velocity of $19 \mathrm{~m} / \mathrm{s}$ which is in reasonable agreement with the measurements.

\section{Conclusions}

In this paper a rather frequent industrial situation is treated according to which a large flammable cloud is ignited by a confined explosion. This occurred in Buncefield. Previous work from the present authors and from other researchers showed that the external explosion in the unburnt gases expelled by the primary confined explosion could be quite violent, sometimes even when the surrounding atmosphere is not explosive (open air). What could happen if the surrounding atmosphere is flammable is the subject of this paper.

A set of experiments is proposed during which the details of the flame propagation were studied. CFD simulations were also performed to investigate the aerodynamics of the flow (OpenFoam software).

The experimental device is composed of a $4 \mathrm{~m}^{3}$ chamber linked to a unconfined $54 \mathrm{~m}^{3}$ volume via a square vent. These two volumes are filled with a stiochiometric propane air mixture. The ignition is obtained using a pyrotechnical match in the $4 \mathrm{~m} 3$ chamber.

Standing alone, the explosion of the $54 \mathrm{~m}^{3}$ volume only produces weak pressure around 10 mbar. Much more violent explosion is triggered when the explosion chamber is used.

If the vent area is large ( $0.7 \mathrm{~m}$ vent $)$, the vortex bubble is formed by the unburnt gases coming from the vessel and burns violently but without triggering a rapid burning of the surrounding atmosphere. The reason is that very little turbulence is generated by the vortex and the rapid combustion of the bubble is not linked to turbulence. In this situation the vessel explosion (including vortex combustion) and the burning of the outside atmosphere are decoupled.

If the vent area is small enough $(0.2 \mathrm{~m})$, the vortex bubble is disrupted (instabilities, boundary layers thickening) and a jet is formed entraining a significant portion of the outside atmosphere. The burning in the jet seems to be calculated suing the jet theory and standard turbulent burning correlations. The explosion overpressure outside can be 10 time larger as compared to the fully unconfined case (no chamber). 
In the case of disruption of the vortex bubble with the small vent, It's possible to develop an engineering tool based on Multi-Energy method which evaluates the quantity of flammable atmosphere implies in the explosion and the flame propagation velocity and the Multi-Energy index. If this situation is present on an industrial site, the explosion can involve an important quantity of gas with high Multi-Energy index.

In the situation of the large vent, it seems to be difficult to evaluate easily the violence of the explosion in an industrial situation. Although we have some hypothesis about the physic of combustion, they need to be verified in specific works.

In general, in an industrial situation, we are not able to define if a structure filled with a flammable cloud provided from outside would be in the first situation with large vent or in the second situation with small vent.

\section{References}

Buncefield investigation report (2008) http://www.buncefieldinvestigation.gov.uk/ reports/index.htm

COOPER M.G. and al, (1986), On the mechanism of pressure generation in vented explosions, Comb. and flame, vol.65, pp 1-14

Harrison A.J. et al, (1987) "External Explosions" as a result of explosion venting ; Combustion Sci. and Tech. n52, pp 91-106

Maxworthy T., (1972) The structure and stability of vortex rings, J. Fluid Mech. n51, part 1, pp 15-32

Maxworthy T., (1977) Some experimental studies of vortex rings, J. Fluid Mech. n81, part 3, pp 465-495

Ch. Proust, E. Leprette, (2010) The dynamics of vented gas explosion, Process Safety Progress, vol. 39, p. 231-235

McCormack P. D. et al., (1972) Flame propagation in a vortex core, Combustion and flame $\mathrm{n}^{\circ} 19$ pp 297-303

Ishizuka S. et al., (1998) Flame speeds in combustible vortex rings, Combustion and flame $\mathrm{n}^{\circ} 113$ pp $542-553$

Chaineaux J. (1993) MERGE Project, final report, E.U. DG XII contract

Gülder O.L. (1990) Turbulent Premixed Flame Propagation Models For Different Combustion Regimes, 23th Symposium (Int.) on Combustion, The Combustion Institute, pp 743-750. 